\title{
The influence of soluble chemical compounds of hexavalent chromium of outbreed male rats causes hemolytic anemia: randomized experimental research
}

\begin{abstract}
Morphological changes of organ of immune system in chronic influence of Hexavalent chromium are researched well but they are not showed in acute poisoning. The goal of our research was the studying of pathomorphological changes of thymus and spleen in the influence of hexavalent chromium in the acute experiment.
\end{abstract}

Materials and Methods of Research: Male rats, weighing 200,0 $20,0 \mathrm{~g}$, were oral dosed one time: the control group (30) - $1 \mathrm{ml}$ of saline, the experimental group (30) - hexavalent chromium at a dose of $75 \mathrm{mg} / \mathrm{kg}$ (LD 50) in the form of potassium dichromate .The rats were taken out of experiment on first, third and seventh days. The histological specimen was colored by hematoxylin and eosin, azure II-eosin. The received data were processed by statistical program Biostat Exc.

Results of Research: $40 \%$ of experimental rats died on the $1^{\text {st }}$ day and $10 \%$ of experimental rats died on the third day. Thymus weight was reduced in $3^{\text {rd }}$ and $7^{\text {th }}$ day-in 2 times, and spleen weight was increased in 1.3 times in comparison with the control. There was a focal and extensive necrosis in the cortical thymus, in the medulla - petechial and extensive hemorrhages; increase in cell number in a state of degradation focal accumulations haemosiderin; formation of segments with lymph follicular hyperplasia was observed. In the vessels of thymus haemolysis of erythrocytes, plasma and soaking fibrinoid swelling of the walls of the arteries was observed. In the spleen focal and extensive hemorrhage; focal necrosis in the white pulp; in the red pulp numerous focal accumulations of hemolyzed red blood cells, haemosiderin was observed.

Conclusion: The development of a mixed dystrophy (parenchyma-mesenchymal)-total haemosiderosis with the development of splenomegaly was observed in the thymus and spleen of experimental rats.

Keywords: Hexavalent chromium; Rats; Acute experiment
Volume I Issue 2 - 2015

NV Zarishnyak,' AN Zhumabayeva,' AR Kaliyev,' BA Djubayeva, ${ }^{2}$ RE Yegemberdiyeva, ${ }^{3}$ SZ Akhmetova'

'Department of Pathological Anatomy, West Kazakhstan State Medical University, Kazakhstan

${ }^{2}$ Department of Normal and topographical anatomy, West Kazakhstan State Medical University, Kazakhstan

${ }^{3}$ Department of Histology, West Kazakhstan State Medical University, Kazakhstan

Correspondence: Natalya Zarishnyak, Assistant of Department of Pathological Anatomy, West Kazakhstan State Medical University, M Ospanov, 0300 19, Aktobe, Maresiev str. 68 , Kazakhstan,Tel 87053383226, Email wengerenko@mail.ru

Received: March 21, 2014 | Published: June 02, 2015

\section{Introduction}

Longstanding activity of the enterprises of mining and processing of chromium in the Western region of Kazakhstan has led to contamination of air, soil and water reservoirs with compounds of three-and Hexavalent chromium, as a result of which was formed a stable chromium biogeochemical province. The particular importance is the soluble hexavalent chromium compounds-chromate and dichromate (potassium and sodium bichromate), which are highly toxic and migration capacity in the biosphere - "soil-plant-animalman". ${ }^{1,2}$ The population of considerable territories has exposed to long-term exposure of hexavalent chromium (CrVI) in low concentrations, which contributes to the development of secondary immunodeficiency's, which have occurred by hyper sensibility to virulent diseases, various hypersensitivity reactions, autoimmune diseases and morbid growths. ${ }^{3}$ Cases of acute poisoning by hexavalent chromium compounds have been registered despite of the implement measures in the production. Morphological changes of central and peripheral organs of the immune system at chronic influence have been well studied, but at an acute poisoning, they are not exposed. ${ }^{4,5}$ That is why the aim of our study was to investigate the pathomorphological changes of thymus and spleen in per oral manipulation of hexavalent chromium in the acute experiment.

\section{Study materials and methods}

Hexavalent chromium was used as a model in form of soluble compounds of potassium dichromate, which is not only xenobiotic (pollutes the environment), but also toxicant (which is used in metal-based manufacturing, leather, textile, chemical, varnish-and-paint, ceramic, match, pyrotechnic industries; it is used for preparation of pigments, tanning materials, seed sterilization). ${ }^{1}$ Potassium dichromate (potassium dichromate, potassium dichromate, GOST 2652-78, mass content is $\mathrm{K}_{2} \mathrm{Cr}_{2} \mathrm{O}_{7}$ upwards of $99,7 \%$ ), was acquired by "Industrial enterprise of chromium compounds" OJSC of Aktobe city. The research was conducted on 60 white outbreed male rats with the mass of $200,0 \pm 20,0 \mathrm{~g}$ obtained from the animal quarters of the West Kazakhstan State Medical University (Kazakhstan, Aktobe), since they do not have the hormonal fremit uses that could affect on the membrane trophic effect of the xenobiotic. The amount of animals in the groups was identified according the methodic recommendations. ${ }^{6,7}$ The division on cells and selection of animals for excretion from the 
experiment was carried out in accordance with the principles of randomization (method of prime numbers). ${ }^{7}$ The animals were divided into two groups: control and experimental. Number of animals in the control and experimental groups was the same as the statistical methods lose sensitivity if the number of animals in the groups differentiates. ${ }^{7}$ Before the conduction of study the animals for 14 days were isolated (sequestration), before the beginning and during the experiment they had been weighed, inspected. The rats had free access to water and food. To the control group (30units), on one occasion through the radiolus had per orally administered $1 \mathrm{ml}$ of physiological solution, to the experimental group (30units) - potassium dichromate solution in a dose of $75 \mathrm{mg} / \mathrm{kg}$ (LD 50). Excretion of the animals from the experiment was carried out in the morning on an empty stomach, at the background of anesthetic sleep, by the method of decapitation on the $1^{\text {st }}$, the $3^{\text {rd }}$ and the $7^{\text {th }}$ days. The conduction of experiment was carried out in accordance with the requirements set out in the order № 442 of the Ministry of Public Health of the Republic of Kazakhstan of 25.07 .2007 .8

The thymus and the spleen had weighed and fixed in $10 \%$ solution of neutral formalin. By the common methods there were performed wiring and filling of the material, preparation of paraffin blocks; hereinafter, had prepared the body sections 5-6 micro IU, which were stained with hematoxylin and eosin, azure II - eosin.

The description of Histopathological changes of the studied organs of experimental animals was carried out on a microscope Leica DM 1000 . The thymus by the following algorithm - a general description of the glands (capsule, the value of lobes, equilibration lobes and the interlobular spaces), the histological structure of the cortex and medulla substances (the increase or decrease of lymphocytes, inversion of panniculuses, focuses of necrosis and hemorrhaging), the state of the arteries and veins of the stroma and parenchyma. The liens: a general description of the red and white pulp, hemorrhaging, focuses of necrosis, a condition of the arteries and veins. The obtained data were processed with the help of the statistical program Biostat Exc ("Biomedical Statistics" 2001, Moscow, Russia) on the computer Pentium IV (Windows). In the research protocols there were recorded: $M$ - arithmetical average, $m$ - standard deviation, $\sigma$-standard error of the arithmetic average, min and max are the values of variation alignments, the dispersion. The normality of the distribution of values in the variation alignments was controlled by the tests of Shapiro-Wilcoxon and Liljefors. By the comparison of data of the control and experimental groups there had been used Student's coefficient. The difference was considered as a statistically significant at the value $\mathrm{P}<0.05$.

\section{Results of research}

$40 \%$ of the experimental animals died on the first day and $10 \%$ of the experimental animals died on the $3^{\text {rd }}$ day. Mass of rats of the experimental group on the $3^{\text {rd }}$ day of the study was for $1.3(\mathrm{P}<0.05)$ times less than the control (Figure 1). Thymus mass decreased by the $3^{\text {rd }}$ and the $7^{\text {th }}$ days - correspondingly by 2.6 and $1.7(\mathrm{P}<0.05)$ times (Figure 2), and the mass of the spleen in the same days had increased by an average of 1.3 times in comparison with the control (Figure 3 ).

\section{Pathomorphological changes of thymus of experimen- tal animals}

The thymus of rats of experimental group was presented in slices of various sizes with preserved division into cortex and medullary substance. Cortex and medullary substance contained a large number of lymphocytes in the state of destruction (with a modified form of vacuoles in the cytoplasm, karyopyknosis or karyolysis) between of which there were apoptotic bodies and cell fragments. In sporadic visual fields of the cortical substance there were defined focuses of necrosis, and of medulla - the devastation with the formation of fields which are consisting of epithelial reticular cells of changed shape, with irregularly shaped nuclei and pathological inclusions in the cytoplasm of eosinophilic color, petechial hemorrhages and orientation of lymphocytes around the extended full-blooded venous vessels. In one case one of the segments of the thymus of experimental animals was presented in a medium-sized slice with the absence of division into cortex and medullary substance, focal accumulations of haemosiderin in the parenchyma and extended lymphatic sinuses that were containing red blood cells and the cells that were in a state of destruction. In the arteries of the thymus (of the interlobular and parenchyma) there was detected intravascular hemolysis of erythrocytes with irregular thickening, dissection and focal destruction of the endothelium (Figure 4). In sporadic visual fields of interlobular spaces there were infiltrated with leucocytes.

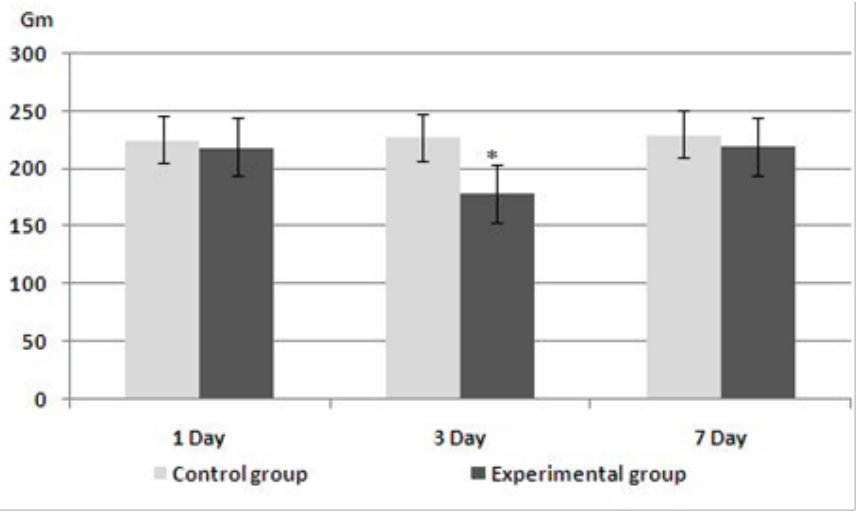

Figure I The dynamics of rats' masses of control and experimental groups.

I - Standard deviation.

*-In comparison with the control.

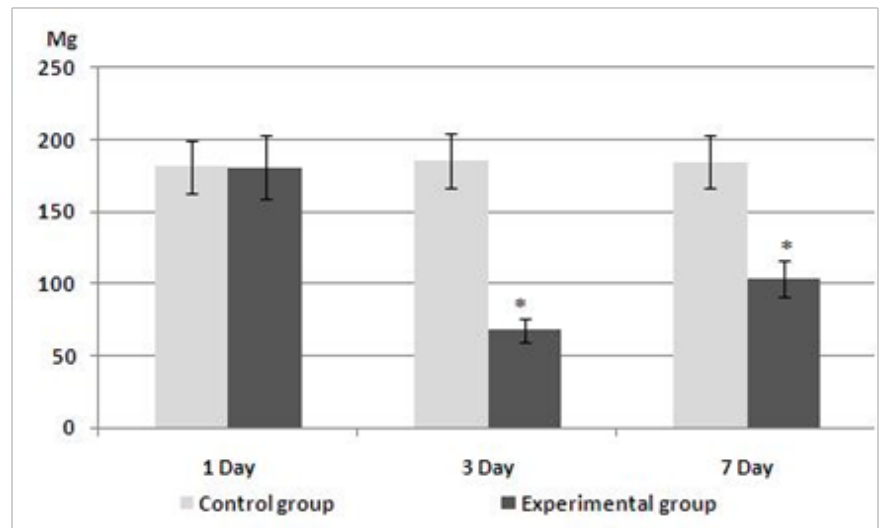

Figure $\mathbf{2}$ The dynamics of thymus's mass of control and experimental groups. I-Standard deviation.

*- In comparison with the control. 


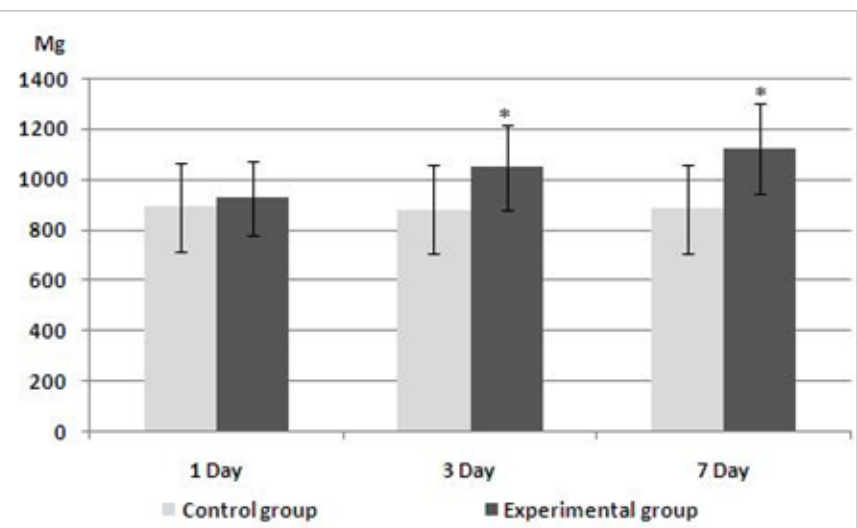

Figure 3 The dynamics of spleen's mass of control and experimental groups.

I-Standard deviation.

*-In comparison with the control.

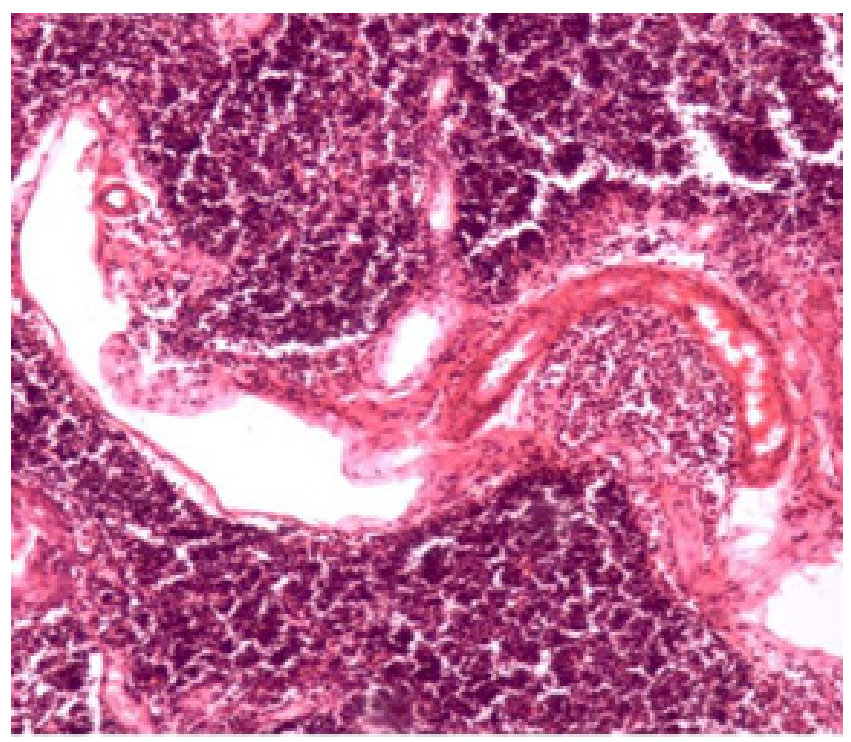

Figure 4 Thymus, the experimental group, I day of the experiment. Hematoxylin and eosin $\times 200$.

In the interlobular arteries has revealed intravascular hemolysis of erythrocytes with irregular thickening, dissection of wall and focal destruction of the endothelium.

\section{The 3rd day of the experiment}

The thymus had consisted of the small lobules, in which there was no clear boundary between the cortex and medullary substance. The interlobular spaces were widened and contained focal accumulations of cellular tissue, adipocytes, lymphocytes, mast cells. The cortical substance of the thymus was vacuated and formed by chordas of epithelial reticular cells in the state of destruction, between of which there were sporadic lymphocytes and cells in the state of destruction; in the medullary substance there was observed focal accumulations of cells in the state of destruction, lymphocytes and macrophages. In contrast to the $1^{\text {st }}$ day of research, in the vessels of the parenchyma there was identified expressed peri vascular hydrops, and in the veins - hemolysis of erythrocytes.

\section{The 7th day of the experiment}

Changes in the right and the left lobe of the thymus of experimental animals were not the same. Both lobes were small in size, but in one of the segments the parenchyma had better preserved. One of the lobes had consisted of clusters of adipocytes (fat cells) and cellular tissue, infiltrated with leukocytes, among of which there were small slices devoid of division into cortex and medullary substance (Figure 5). Another lobe was composed of lobules of various sizes with the inversion of panniculuses; with the formation in the cortical substance of lymphoid follicles; with the absence of division into cortex and medullary substance. The wall of the interlobular arteries had expressed eosinophilic staining, was significantly thickened, and in sporadic areas had a homogeneous structure, the lumen had sharply narrowed and as well as the $1^{\text {st }}$ and the $3^{\text {rd }}$ days was filled with hemolyzed erythrocytes (Figure 6). In sporadic visual fields there were observed extravasations in the interlobular space. The parenchyma of lobules had consisted of lymphocytes of different sizes, of segmented neutrophils, of singular plasmocytes, macrophages, cells in the state of destruction. Epithelial reticular cells with distinct morphological changes (of irregular shape, with pathological inclusions in the cytoplasm, with large nuclei) had formed focal accumulations, and in sporadic vision fields there were identified in them epithelial canaliculus. In the lobules with cortical substance in the form of lymphoid follicles (Figure 7) there were defined focuses of the pigment of various sizes (Figure 8), and in rarefied medullary substances-the lymphatic sinuses (Figure 7) that are containing the cells of the state of degradation, erythrocytes and hemolyzed erythrocytes.

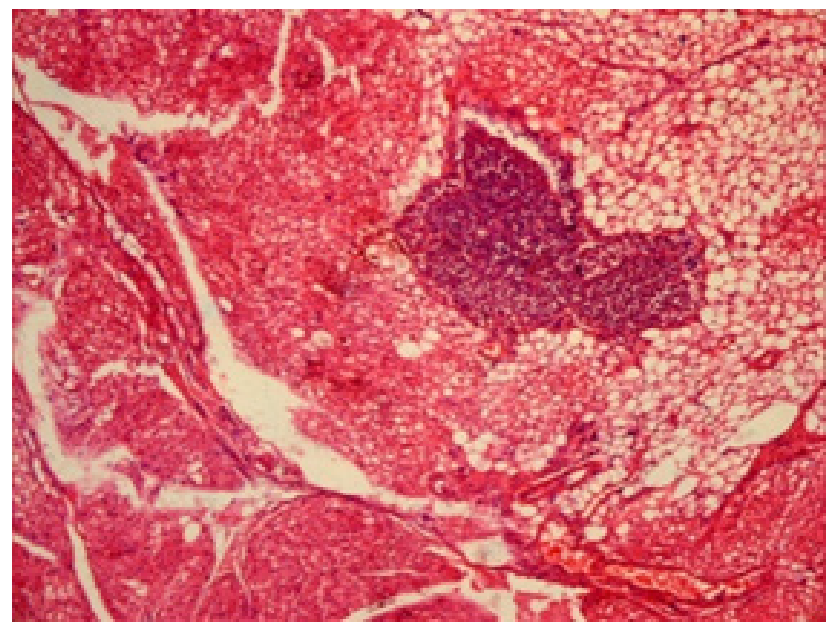

Figure 5 Thymus, the experimental group, 7 day of the experiment. Hematoxylin and eosin $\times 100$.

Thymus is represented by accumulations of adipocytes (fat cells) and loose connective tissue, infiltrated with leukocytes, between of which there is a small slice devoid of division into cortex and medullary substance.

In one case, in the thymus there was identified a cystic cavity of irregular shape that was containing the lymphocytes and the cells in the state of destruction, the wall of which had been irregularly thickened and had been formed by several layers of epithelial cells. The thymus of dead rats of experimental group $(26.6 \%)$ in the $1^{\text {st }}$ day of the study had consisted of lobes that were formed by one or two slices with the absence of divisions into cortex and medullary substances. The parenchyma of lobules was represented by lymphocytes of various sizes, the cells in the state of destruction, macrophages sporadic 
plasmocytes and segmented neutrophils between of which there were small focuses of pigment. In the $3.4 \%$ of cases in the thymus of dead animals had preserved the division into cortex and medullary substances, but there was extensive necrosis of the cortical and hemorrhages in the medullary substance. On the $3^{\text {rd }}$ day of research in the thymus of dead rats $(10 \%)$ were found extensive necrosis of the parenchyma. In the animals of the experimental group in all days of the research in the thymus there were identified numerous segments that were consisting of only the epithelial reticular cells in the state of destruction, between of which there had been located sporadic cells. The number of such lobules was increased by the $3^{\text {rd }}$ and $7^{\text {th }}$ days of the experiment.

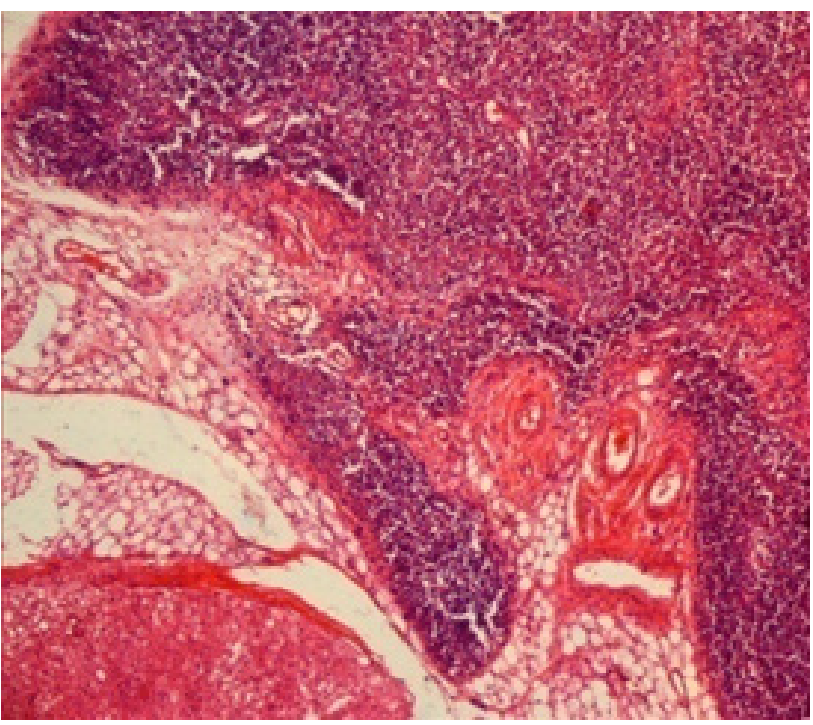

Figure 6 Thymus, the experimental group, 7 day of the experiment. Hematoxylin and eosin $\times 100$.

The interlobular expansion of space, filled with adipocytes and loose connective tissue. Interlobular artery wall has a distinct eosinophilic staining considerably thickened homogeneous structure, lumen sharply narrowed and filled with hemolyzed erythrocytes.

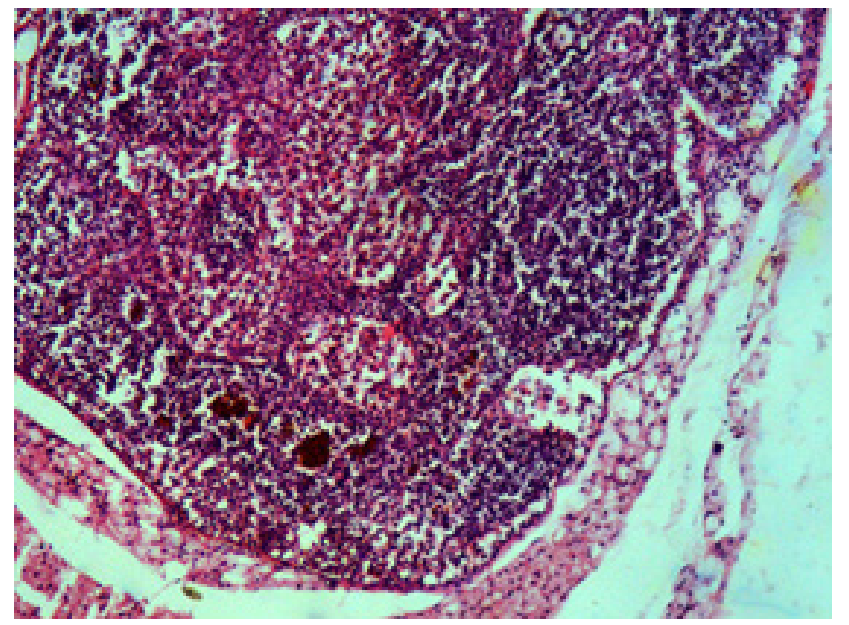

Figure 7 Thymus, the experimental group, 7 day of the experiment Hematoxylin and eosin $\times 200$.

Each lobe contains a cortex in the form of lymphoid follicles in medullary substance - the lymph sinuses.

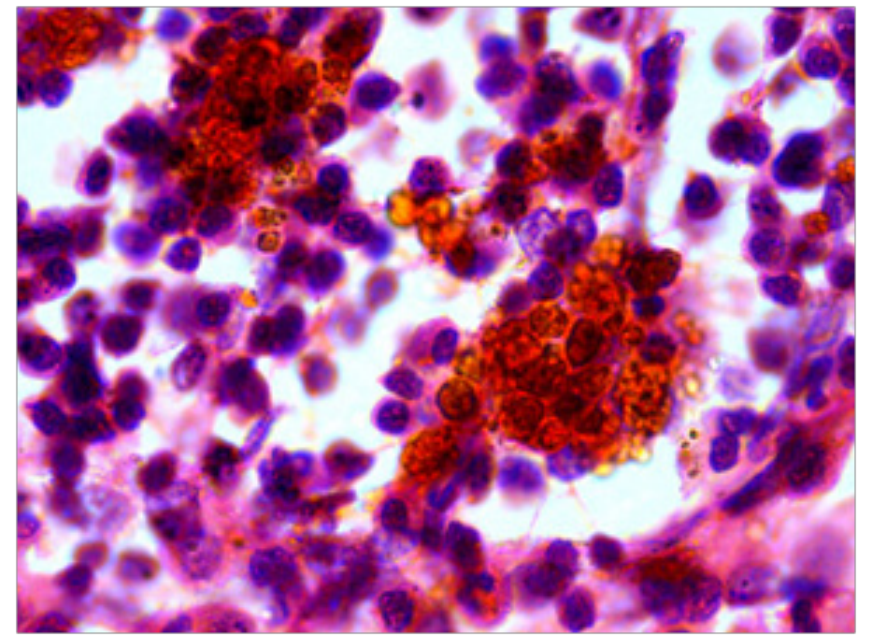

Figure 8 Thymus, the experimental group, 7 day of the experiment. Hematoxylin and eosin $\times 1000$.

In medullary substance slices-accumulations of haemosiderin of various sizes, epithelial reticular cells in a state of dystrophy, the cells in a state of destruction.

\section{Pathomorphological changes of lien of the experimen- tal animals}

The $1^{\text {st }}$ day of the experiment: Trabecular arteries of the lien were of irregular shape, filled with hemolyzed erythrocytes. The wall of the arteries was unevenly thickened, with areas of exfoliated endothelium and delaminate muscle layer, infiltrated by leukocytes. In the red pulp - numerous focal accumulations of hemolyzed red blood cells, enhanced venous sinuses were also filled with hemolyzed erythrocytes. In the white pulp - follicles and marginal zones, peri arterial lymphoid connections (PALS) were of small size, singular. There was marked a peri vascular hydrops of the central artery of the follicles with an uneven thickening and plasmorrhagia of the wall and destruction on a significant extent of the endothelial lining. In sporadic vision fields there were observed focal hemorrhages in the follicles, PALS and red pulp. In the red and white pulp, there were a significant number of lymphocytes (of the modified form with vacuoles in the cytoplasm, and with karyolysis and karyopyknosis) and reticular cells (with pathological inclusions to the cytoplasm of eosinophilic color karyolysis) in the state of destruction.

The $3^{\text {rd }}$ day of the experiment: In the red pulp, in contradistinction to the first days of the study, between the fields of hemolyzed erythrocytes there were numerous focal accumulations of haemosiderin of various sizes and shapes. In the white pulp (follicles, marginal zone and PALS) of the lien there were prevailed the macrophages, the cells in the state of destruction, between of which there were single lymphocytes. Trabecular arteries and veins - irregularly shaped, were filled with hemolyzed erythrocytes, their wall were unevenly thickened and sometimes were of a homogeneous structure.

The $7^{\text {th }}$ day of the experiment: In the red pulp there was observed focal accumulations of lymphocytes of various sizes, which gave it patchy appearance. Follicles, marginal zone, PALS of white pulp were expanded and rarefied, were formed by reticulum cells in the state of dystrophy, between of which there were singular lymphocytes, the cells in the state of destruction and macrophages. Extensive extrav- 
asations with hemorrhagic impregnation of parenchyma of the lien were revealed in dead animals in the $1^{\text {st }}$ day of the study (Figure 9), and on the $7^{\text {th }}$ day - there was in the parenchyma no division to structural components (red and white pulp) and it consisted of reticular cells, collections of lymphocytes in the state of destruction, between of which there were focuses of pigment, the macrophages (Figure 10).

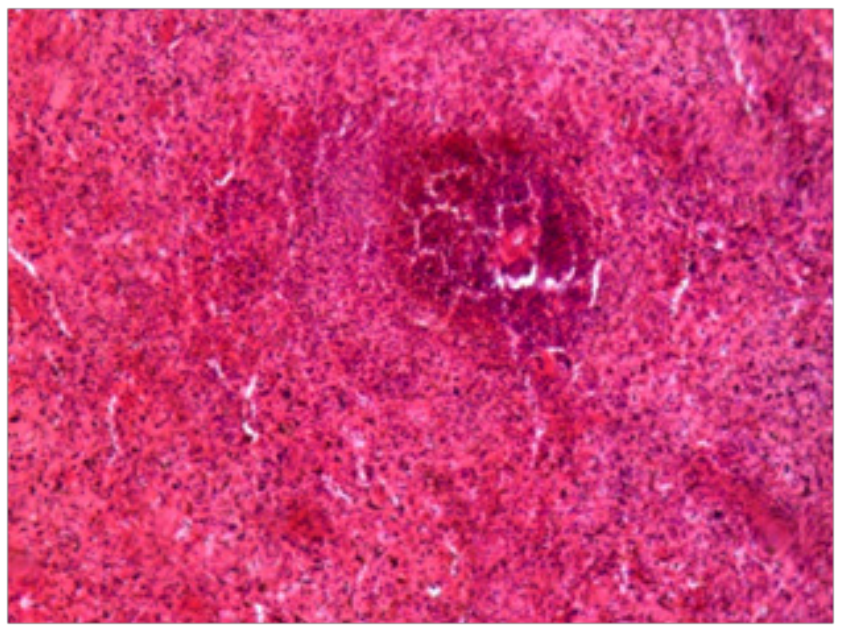

Figure 9 Lien, the experimental group, I day of the experiment. Hematoxylin and eosin $\times 100$.

Extensive extravasation with hemorrhagic impregnation of parenchyma of the lien.

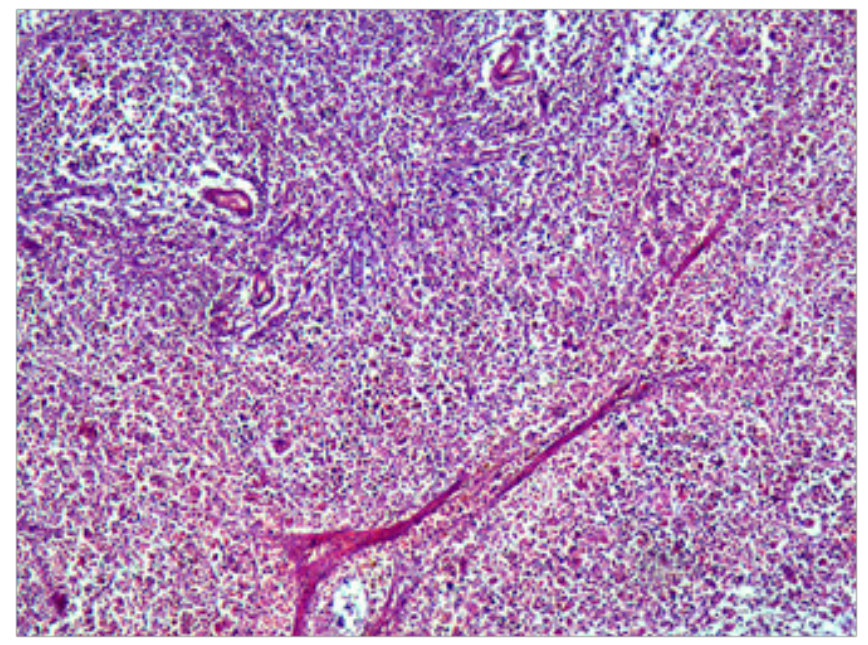

Figure 10 Spleen, the experimental group, 7 day of the experiment Hematoxylin and eosin $\times 100$.

In the parenchyma of lien there is no division into structural components (red and white pulp) and it consists of reticular cells, collections of lymphocytes in a state of destruction, between of which there are lobules of pigment, macrophages. The arteries of red and white pulp are sharply narrowed, the

wall of homogeneous structure.

\section{Discussion and conclusion}

The water-soluble hexavalent chromium compounds are more toxic than the insoluble compounds of metal. Reducing the valency of $\mathrm{Cr}$ VI to Cr III takes place in the stomach of animals under the influence of acidic media. Basically, Cr VI is absorbed through sulfate ion channels in the small intestine, the alkaline environment of which increases the stability of xenobiotic. ${ }^{1,2}$ In contrast to the human, in the rats only $3.1 \%$ of the administered dose is absorbed. ${ }^{2}$ The compounds $\mathrm{Cr}$ III are absorbed in the small intestine as a result of passive diffusion and only $0.33 \%$ of the administered dose. ${ }^{9}$ It can be assumed that the main toxic effects on the animal organism exert anyhow the compounds of Cr VI. Cr VI soluble compounds are absorbed in the blood by erythrocytes, leukocytes, platelets, and only a small amount is associates with plasma proteins. ${ }^{10-15}$ On the first day of exposure, $60-65 \% \mathrm{Cr}$ VI is absorbed by erythrocytes, to ten days, this connection increases to $80 \% .^{16,17}$

In erythrocytes the $\mathrm{Cr}$ (VI) strongly communicates with the betachain of hemoglobin ${ }^{18}$ and blocks in them erythrocytic 6-GPD. ${ }^{19}$ The inhibition of this biocatalyst leads to the reduction of ATP in erythrocytes, necessary for functioning of the "sodium pump". ${ }^{19}$ Consequently, the ionic equilibrium is disturbed (erythrocytes lose potassium), here arises the swelling of cells and hemolysis. The time of hemolysis depends on the dose and hexavalent chromium exposure. ${ }^{19,20} \mathrm{Cr}$ VI causes a polymorphism of the genes encoding proteins of anion of transport and its determination in erythrocytes can serve as a biomarker of exposure to this xenobiotic on the human body and animals. ${ }^{21}$ In addition, the absorption of Cr VI by erythrocytes reduces their life expectancy and leads to the development of anemia. ${ }^{18}$

The generally accepted point of view, that at the basis of toxico kinetics and toxicodynamics the $\mathrm{Cr}$ VI is its absorption of formed elements of the blood ${ }^{10-15}$ and the development of oxidative stress in cells of organs and tissues, due to the reduction in $\mathrm{Cr} \mathrm{V}$, IV, III with occurrence of active oxygen species, which cause damage of cellular proteins, lipids and DNA. ${ }^{22-29}$ List of publications, where this viewpoint is a major, can be continued. In our opinion, here we have a contradiction. As the Cr VI causes the oxidative stress in cells of organs and tissues if it accumulates in the formed elements of blood and already in them it is recovering in the $\mathrm{Cr}$ III. ${ }^{10-15} \mathrm{We}$ believe that the main pathogenetic mechanism of influence of this chemical element is the development of hemolytic anemia and as a consequence of hypoxia of oxidative stress that prove the results of our investigation.

It allocates hemolytic anemia with extra vascular and intravascular hemolysis of erythrocytes. ${ }^{30}$ The red blood cells at extra vascular hemolytic anemia (the compensated stage of hemolytic anemia) are destroyed in the lien macrophages, Kupffer cells of the liver and bone marrow macrophages. ${ }^{31}$ Intravascular hemolysis (decompensate stage of hemolytic anemia) causes a disturbance of the colloidosmotic properties of blood and promotes impregnation vessel walls by plasma proteins (plasmatic impregnation, fibrinoid swelling); haemosiderin deposition in organs and tissues (total haemosiderosis). Massive destruction of red blood cells observed and in the lien, which causes splenomegaly. ${ }^{30,31}$ Hemolytic anemia leads to the development of oxidative stress. ${ }^{32}$

In our research there were identified as intravascular hemolysis of erythrocytes - in the thymus and the lien of rats of the experimental group (in all days of investigation) and increased destruction of red blood cells in the red pulp of the lien with the development of megalosplenia. Hemolysis of erythrocytes in the cavity of vessels had caused plasmatic impregnation of the walls of arteries and veins, as the result it involves to the damage of the basal and elastic membranes of endothelial cells and led to an increase of vascular permeability with the development of peri vascular swelling and petechial hemorrhages, and focal destruction of the wall-to extensive extravasations $\left(1^{\text {st }}\right.$ and 
$3^{\text {rd }}$ days)..$^{30,31}$ On the $7^{\text {th }}$ day of the experiment in the vessel walls of the thymus, the lien there had been noted fibrinoid swelling - the destruction of the intercellular substance (areas with a homogeneous structure) with expressed wall thickening and luminal narrowing, which is in histological preparations (hematoxylin and eosin, azureII-eosin stain) of experimental group was characterized by a bright red colored walls of the arteries and veins (fibrinoid is stained with eosin into the red color). ${ }^{33}$ Haemosiderin is formed only intra cellularly. ${ }^{34}$ In our experiment sideroblasts could be the epithelial reticular cells of the thymus, as evidenced by the pathological eosinophilic color inclusions in the cytoplasm of epithelial reticular cells and identified clusters of haemosiderin in the parenchyma. ${ }^{31}$

In such a manner, in the presence of a semelincident per oral administration of $50 \mathrm{LD}(75 \mathrm{mg} / \mathrm{kg})$ of hexavalent chromium to the white outbreed tom rats in the thymus and the lien there was observed the development of a mixed dystrophia (parenchymal-mesenchymal) - total hemosiderosis with the development of megalosplenia.

\section{Acknowledgements}

None.

\section{Conflict of interest}

The author declares no conflict of interest.

\section{References}

1. Mamyrbayev AA. The toxicology of chromium and its compounds Aktobe. Kazakhstan; 2012.

2. Zhitkovich A. Chromium in Drinking Water:Sources, Metabolism, and Cancer Risks. Chem Res Toxicol. 2011;24(10):1617-1629.

3. Imankulov ZhI, Goncharova TG, Yakovleva NA, et al. Results of investigations the chromium content in air, water, soil, plants of Aktobe region. Materials of the VI International Scientific and Practical Conference "Heavy metals and radionuclides in the environment". Kazakhstan; 2010. 1:177-180.

4. Shrivastava R, Upreti RK, Seth PK, et al. Effects of chromium on the immune system. FEMS Immunol Med Microbiol. 2002;34(1):1-7.

5. Bieger WP. Characterization of immune reactions to metals. European Cells and Materials. 2003;5(1):17-26.

6. The order No. 708 of the Ministry of Public Health and Social Development of the Russian Federation (Russian Health and Social Development) of 23 August, 2010 "About confirmation of Rules of good laboratory practice".

7. National Standard of the Russian Federation, GOST R 53434-2009 "Principles of Good Laboratory Practice".

8. Order of the Minister of Health of the Republic of Kazakhstan. On approval of the Rules of preclinical researches, biomedical experiments and clinical tests in the Republic of Kazakhstan. Kazakhstan; 2007. 442 p.

9. Dowling HJ, Offenbacher EG, Pi-Sunyer FX. Absorption of inorganic, trivalent chromium from the vascularly perfused rat small intestine. $J$ Nutr. 1989;119(8):1138-45.

10. Wiegand HJ, Ottenwälder H, Bolt HM. Recent advances in biological monitoring of hexavalent chromium compounds. Sci Total Environ. 1988;71(3):309-315.

11. Wiegand HJ, Ottenwälder H, Bolt HM. Fast uptake kinetics in vitro of ${ }^{51} \mathrm{Cr}$ (VI) by red blood cells of man and rat. Arch Toxicol. 1985;57(1):3134.
12. Lupescu A, Jilani K, Zelenak C, et al. Hexavalent chromiuminduced erythrocyte membrane phospholipid asymmetry. BioMetals. 2012;25(2):309-318.

13. Coogan TP, Squibb KS, Motz J, et al. Distribution of chromium within cells of the Blood. Toxicol Appl Pharmacol. 1991;108(1):157-166.

14. Gao M, Levy LS, Braithwaite RA, et al. Monitoring of Total Chromium in Rat Fluids and Lymphocytes Following Intra tracheal Administration of Soluble Trivalent or Hexavalent Chromium Compounds. Hum Exp Toxicol. 1993;12(5):377-82.

15. Kattlove HE, Spaet TH. The effect of Chromium on Platelet Function in Vitro. Blood. 1970;35(5):659-68.

16. Levina EN. General toxicology of metals. Leningrad: Medicine. 1972.

17. Sedov VV, Kovalchuk ID. Features of behavior in the animal organism of certain radioactive isotopes, depending on the physico-chemical properties of the compounds. Distribution and biological effects of radioactive isotopes: a collection of articles. In: DMS YI, editor. Moskaleva: Atomizdat; 1966. p. 129-38

18. Adjroud O. Effects of potassium dichromate on haematological parameters in female and male Wistar albino rats. Ass Univ Bull Environ Res. 2009;12(2):87-90.

19. Smirnov IM. Effect of six-and trivalent chromium on the state of red blood cells in experimental animals during the intake to body with water. Environmental health issues. Collection of scientific works. Russia: $\mathrm{MH}$ USSR, ASK USSR; 1987. p. 78-79.

20. Stana L, Trif A, Stana LG, et al. Comparative Study of the Potassium Dichromate Effect on the Osmotic Resistance of Rat Erythrocyte Membrane. Animal Science and Biotechnol. 2010;43(1):425-429.

21. Qu Q, Li X, An F, et al. Cr VI exposure and biomarkers: Cr in erythrocytes in relation to exposure and polymorphisms of genes encoding anion transport proteins. Biomarkers. 2008;13(5):467-477.

22. Stohs SJ, Bagchi D, Hassoun E, et al. Oxidative mechanisms in the toxicity of chromium and cadmium ions. J Environ Pathol Toxicol Oncol. 2001;20(2):77-88.

23. Patlolla AK, Barnes C, Yedjou C, et al. Oxidative Stress, DNA Damage, and Antioxidant Enzyme Activity Induced by Hexavalent Chromium in Sprague-Dawley Rats. Environ Toxicol. 2009;24(1):66-73.

24. Dayan AD, Paine AJ. Mechanisms of chromium toxicity, carcinogenicity and allergenicity: Review of the literature from 1985 to 2000. Hum Exp Toxicol. 2001;20(9):439-451.

25. Goulart M, Batoreu MC, Rodrigues AS, et al. Lipoperoxidation products and thiol antioxidants in chromium exposed workers. Mutagenesis. 2005;20(5):311-315.

26. Wang XF, Xing ML, Shen Y, et al. Oral administration of Cr (VI) induced oxidative stress. DNA damage and apoptotic cell death in mice. Toxicology. 2006;228(1):16-23.

27. Nigam A, Priya S, Bajpai $P$, et al. Cytogenomics of hexavalent chromium $(\mathrm{Cr} 6+)$ exposed cells: A comprehensive review. Indian $J$ Med Res. 2014;139(3):349-370.

28. Shadreck M, Mugadza T. Chromium, an essential nutrient and pollutant: A review. African J Pure Appl Chemistry. 2013;7(9):310-317.

29. Lushchak OV, Kubrak OI, Nykorak MZ, et al. The effect of potassium dichromate on free radical processes in goldfish: Possible protective role of glutathione. Aquat Toxicol. 2008;87(2):108-114.

30. Dhaliwal G, Cornett PA, Tierney LM. Hemolytic anemia. Am Fam Physician. 2004;69(11):2599-2606.

31. Strukov AI, Serov VV, Sarkisov DS. General human pathology: guidance for doctors. P Medicine. 1990. 
32. Boretti FS, Buehler PW, D'Agnillo F, et al. Sequestration of extracellular hemoglobin within a haptoglobin complex decreases its hypertensive and oxidative effects in dogs and guinea pigs. $J$ Clin Invest. 2009;119(8):2271-2280.
33. Kaliteevskiy P. Macroscopic differential diagnosis of pathological processes. Pract guid. Miklosh LLC 384. 1993.

34. Akchurin SV, Demkin GP. General pathological anatomy. USA: Lecture notes for universities and colleges; 2009 